\title{
SEVERE AND PROLONGED CHOLESTASIS CAUSED BY TRIMETHOPRIM-SULFAMETHOXAZOLE: A CASE REPORT
}

doi: 10.1590/S1807-59322009000100014

Luciana C. Faria, ${ }^{\mathrm{I}}$ Clarissa C. Resende, ${ }^{\mathrm{I}}$ Cláudia A. Couto, ${ }^{\mathrm{III}}$ Osvaldo F.M. Couto, ${ }^{\mathrm{I}}$ Lúcia P.C. Fonseca, ${ }^{\mathrm{III}}$ Teresa Cristina A. Ferrari, , II

\section{INTRODUCTION}

Trimethoprim-sulfamethoxazole (TMP-SMX) is a widely used antibiotic in the prophylaxis and treatment of a variety of common infections. Hepatic injuries caused by TMPSMX are considered rare and are classified as unpredictable or idiosyncratic types of hepatotoxic reactions. ${ }^{1}$ The pattern of injury may be characterized by hepatocellular necrosis, ${ }^{1,2}$ mixed hepatocellular-cholestasis, ${ }^{1,3,4}$ or cholestasis..$^{5-7}$ We describe a case of severe and prolonged cholestasis, which arose 30 days after a 5-day course of TMP-SMX treatment, and provide a review of related cases.

\section{CASE DESCRIPTION}

A 33-year-old woman with a past history of recurrent urinary tract infection was treated with TMP-SMX for 5 days. One month later, she developed malaise, fatigue, anorexia, nausea, vomiting, fever, jaundice, dark urine, and a diffuse pruriginous rash. She had been previously exposed to this agent in the past. She denied alcohol consumption and any previous comorbid condition, and she had not taken any other medication during the last 3 months. The patient was previously hospitalized in 2 other institutions. Laboratory tests performed during the second admission revealed a total bilirubin level of $26.8 \mathrm{mg} / \mathrm{dL}$ (upper normal

I Alfa Institute of Gastroenterology, University Hospital, Federal University of Minas Gerais - Belo Horizonte/MG, Brazil.

"I School of Medicine, Department of Internal Medicine - Belo Horizonte/ MG, Brazil.

III Department of Pathology and Legal Medicine, School of Medicine, Federal University of Minas Gerais - Belo Horizonte/MG, Brazil.

Email: lucostafaria@hotmail.com

Tel.: 55313409.9247 / 3409.9253 limit [UNL] $1.2 \mathrm{mg} / \mathrm{dL})$, conjugated bilirubin of $19.6 \mathrm{mg} /$ $\mathrm{dL}$ (UNL $0.3 \mathrm{mg} / \mathrm{dL}$ ), aspartate aminotransferase (AST) of $154 \mathrm{IU} / \mathrm{L}$ (UNL $46 \mathrm{IU} / \mathrm{L}$ ), alanine aminotransferase (ALT) of $63 \mathrm{IU} / \mathrm{L}$ (UNL $66 \mathrm{IU} / \mathrm{L})$, alkaline phosphatase of $226 \mathrm{IU} / \mathrm{L}$ (UNL $126 \mathrm{IU} / \mathrm{L}$ ), and albumin of $2.3 \mathrm{~g} / \mathrm{dL}$. Abdominal ultrasound and computed tomography were normal. Tests for antinuclear antibody, antibodies against hepatitis $\mathrm{C}$ virus, and human immunodeficiency virus (HIV), total anti-HBc, and hepatitis B surface antigen were all negative. Liver biopsy demonstrated severe cholestasis, with bile inside the hepatocytes and numerous bile casts in the canaliculi, predominantly in the pericentrilobular zone. Small numbers of mononuclear cells and neutrophils infiltrated into the vicinity of the cholestasis without any other inflammatory activity (portal or periportal) or fibrosis. The liver architecture was intact (Figure 1). As the jaundice

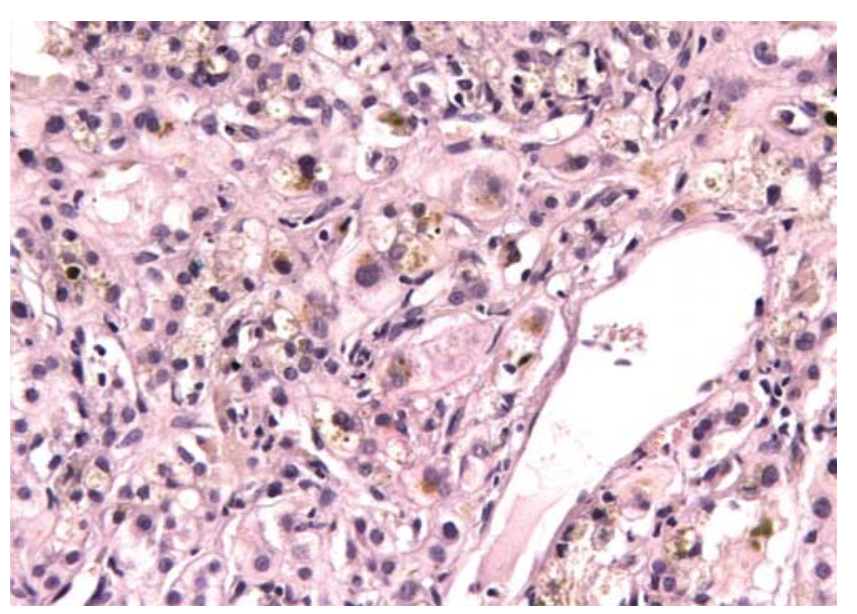

Figure 1 - Severe cholestasis with bile inside the hepatocytes and numerous bile casts in the canaliculi, predominantly in the pericentrilobular zone; small numbers of mononuclear cells and neutrophils infiltrate into the vicinity of the cholestasis $(\mathrm{HE}, \times 400)$ 
persisted, the patient developed pruritus and lost $15 \mathrm{Kg}$ over 2 months. The patient was then referred to our institution for continued investigation. At that time, the total bilirubin was $14.2 \mathrm{mg} / \mathrm{dL}$, with a conjugated bilirubin level of $13.3 \mathrm{mg} /$ $\mathrm{dL}$, alkaline phosphatase of 1,273 IU/L, gamma glutamyl transpeptidase (GGT) of 877 IU/L (UNL 43 IU/L), AST of 147 IU/L, ALT of 103 IU/L, International Normalized Ratio (INR) of 1.4 , albumin of $2.6 \mathrm{~g} / \mathrm{dL}$, and globulins of $3.4 \mathrm{~g} /$ $\mathrm{dL}$. The patient exhibited normocytic and normochromic anemia (hemoglobin $10.8 \mathrm{~g} / \mathrm{dL}$ ), with normal white blood cell (without eosinophilia) and platelet counts. Plasma levels of amylase, lipase, urea, creatinin, and glucose were normal. Serologies for hepatitis A, B, and C and anti-HIV were negative, as were the autoantibodies (antimitochondrial, anti-smooth muscle, anti-liver kidney muscle [LKM]-1, antinucleus, antithyroid peroxidase, and antithyroglobulin). Caeruloplasmin, ferritin, alpha-1-antitrypsin, TSH, free thyroxine (fT4), IgG, IgM, IgA and alpha-fetoprotein levels were all normal. Upper digestive endoscopy and endoscopic retrograde cholangiopancreatography (ERCP) demonstrated no abnormalities. Abdominal ultrasound revealed non-specific splenomegaly. Liver biopsy was repeated with equivalent results. The pruritus was unresponsive to cholestyramine associated with dexclorfeniramine, but it was successfully treated with cholestyramine and hydroxyzine. The patient presented with slow and progressive improvement of all clinical and laboratory parameters, with complete normalization of the bilirubin levels in 8 months, alkaline phosphatase in 16 months, and GGT in 35 months (Figure 2). She regained weight and is currently asymptomatic and doing well. The patient also exhibited normal liver function during a followup period of 5 years after symptom onset.

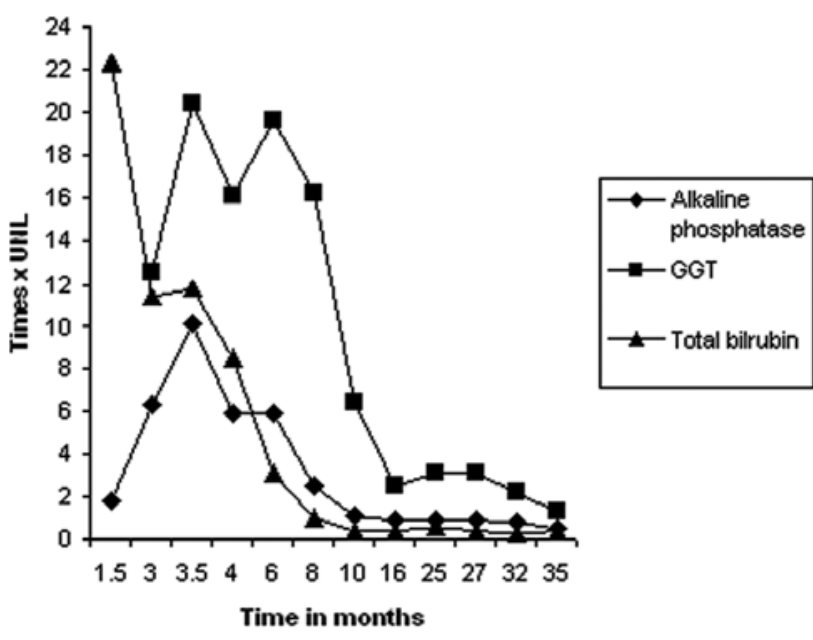

Figure 2 - Evolution of alkaline phosphatase, gamma glutamyl transpeptidase (GGT), and total bilirubin; UNL: upper normal limit

\section{DISCUSSION}

We report a case of severe cholestasis accompanied by important systemic repercussion, as evidenced by weight loss (15 Kg in 2 months), hypoalbuminemia, anemia, and a protracted course of disease. The exhaustive investigation of other etiologies of liver damage strongly suggested a causal association between TMP-SMX and the hepatic lesion in this case. Liver biopsy demonstrated cholestasis with minimal lobular inflammatory activity and necrosis.

Drug-induced liver injury due to TMP-SMX is rare and is classified as either an unpredictable or idiosyncratic type of hepatotoxic reaction. The pattern of injury may be characterized by hepatocellular necrosis, ${ }^{1,2}$ mixed hepatocellular-cholestasis, ${ }^{1,3,4}$ or cholestasis. ${ }^{5-7}$ The majority of the reported cases of TMP-SMX-induced cholestasis were reviewed and are summarized in Table 1.

In previous reports, TMP-SMX-induced intrahepatic cholestasis was associated with minimal hepatocellular inflammation or necrosis, symptom onset of between a few days and a month after the beginning of therapy, and a clinical course that usually subsides within a few months. ${ }^{5,8-11}$ The etiologic role of TMP-SMX has been confirmed in a few cases by either inadvertent or deliberate rechallenge. .,, $10^{-10}$ In the present case, rechallenge was not accomplished because of the clinical severity and prolonged course of the disease. The time interval between drug discontinuation and initiation of symptoms in the present case was quite long (30 days). However, we could not rule out the possibility of the presence of mild symptoms before they became severe enough to be noticed by the patient. Furthermore, the latency period between initial ingestion of the drug and hepatic manifestations could range from 5 to 90 days. ${ }^{12}$

A few reports of prolonged cholestasis induced by TMP-SMX have already been published. ${ }^{6,713}$ Muñoz et al. described a case of intrahepatic cholestasis associated with prominent hepatocyte lysosomal inclusions suggestive of phospholipidosis by electron microscopy, and of severe pruritus that lasted 8 months. The symptoms eventually led to the initiation of plasmapheresis. ${ }^{7}$ Kowdley et al. reported two cases of severe, prolonged cholestasis in which bilirubin normalized within 11-12 months and mild alkaline phosphatase and GGT level abnormalities lasted for approximately 2 years. ${ }^{6}$

Two cases of TMP-SMX-induced cholestatic liver damage with ductopenia (vanishing bile duct syndrome) have also been reported. ${ }^{14,15}$ Yao et al. reported one such case in which jaundice appeared after a 5-day course of therapy and progression to liver failure led to liver transplantation 9 months after the onset of the symptoms. ${ }^{14}$ The possibility of such clinical evolution should alert physicians to the 
Table 1 - Cases of Trimethoprim-sulfamethoxazole (TMT-SMX) induced cholestasis

\begin{tabular}{|c|c|c|c|c|c|c|}
\hline Publication & Age & Sex & $\begin{array}{l}\text { Time interval between the use of } \\
\text { TMT-SMX and the beginning of } \\
\text { the symptoms }\end{array}$ & $\begin{array}{l}\text { Total bilirubin } \\
\quad(\mathrm{mg} / \mathrm{dL})\end{array}$ & $\begin{array}{l}\text { Time interval between the } \\
\text { interruption of TMT-SMX and } \\
\text { normalization of bilirubin }\end{array}$ & Rechallenge \\
\hline Ogilvie et al., 1980 (8) & 70 & $\mathrm{~F}$ & Just after a 7-day course & 22.3 & 6 months & $\begin{array}{l}\text { Yes, inadvertently, } \\
\text { positive }\end{array}$ \\
\hline Nair et al., 1980 (9) & 61 & M & After 1 month on therapy & 8.8 & 1 month & No \\
\hline $\begin{array}{l}\text { Steinbrecher and } \\
\text { Mishkin, } 1981 \text { (10) }\end{array}$ & 53 & $\mathrm{~F}$ & Just after a 10-day course & 9 & 1 month & $\begin{array}{l}\text { Yes, inadvertently } \\
\text { and after informed } \\
\text { consent, both } \\
\text { positive }\end{array}$ \\
\hline Coto et al., 1981 (11) & 55 & M & In the 3 rd week of therapy & 7.1 & 1.5 month & No \\
\hline $\begin{array}{l}\text { Abi-Mansur et al., } \\
1981(5)\end{array}$ & 52 & $\mathrm{~F}$ & In the 7 th day of therapy & 11.2 & 3 months & No \\
\hline Muñoz et al., 1990 (7) & 60 & $\mathrm{~F}$ & In the 4th day of therapy & 37 & 8 months & No \\
\hline Kowdley et al., 1992 (6) & 48 & $\mathrm{~F}$ & In the 10 th day of therapy & 34.8 & 11 months & No \\
\hline Kowdley et al., 1992 (6) & 43 & $\mathrm{~F}$ & In the 7 th day of therapy & 36.8 & 12 months & No \\
\hline Altraif et al., 1994 (14) & 30 & M & In the 4th day of therapy & 2.5 & $\begin{array}{c}\text { Few weeks, but pruritus persisted } \\
\text { for longer than one year }\end{array}$ & No \\
\hline $\begin{array}{l}\text { Ruiz-Irastorza et al., } \\
1996 \text { (13) }\end{array}$ & 38 & $\mathrm{~F}$ & 1 day after a single dose & 10.7 & $\begin{array}{l}5 \text { months: total bilirubin } 1.5 \\
\text { One year: total bilirubin normal }\end{array}$ & No \\
\hline Yao et al., 1997 (15) & 57 & M & In the 5 th day of therapy & 40.4 & $\begin{array}{l}\text { It did not normalize. Because of } \\
\text { clinical deterioration, the patient } \\
\text { underwent ortthotopic liver } \\
\text { transplantation } 9 \text { months after the } \\
\text { beginning of symptoms }\end{array}$ & No \\
\hline $\begin{array}{l}\text { Kouklakis et al., } \\
2007 \text { (4) }\end{array}$ & 30 & M & $\begin{array}{l}11 \text { days after a } \\
15 \text {-day course }\end{array}$ & 6.9 & 40 days & No \\
\hline
\end{tabular}

F: female; M: male

potentially serious cholestatic-pattern of hepatotoxicity associated with this commonly used drug.

The present report and other similar cases demonstrate that cholestasis can be the most prominent feature of TMP-SMX-induced liver damage. The high frequency of TMP-SMX prescription contrasts with the rarity of well-documented examples of drug-related cholestasis or hepatic damage due to the use of TMP-SMX. Nevertheless, the present case and other previous cases emphasize the importance of considering drug-induced liver disease during differential diagnosis of patients receiving this drug. This is particularly critical since TMP-SMX administration must be stopped immediately in order to improve the outcome despite the rare need for patients to require liver transplantation as a consequence of dug-induced hepatotoxic injury. ${ }^{15}$

\section{REFERENCES}

1. Berg PA, Daniel PT. Co-trimoxazole-induced hepatic injury - an analysis of cases with hypersensitivity-like reactions. Infection. 1987;15 Suppl 5:S259-S264.

2. Zaman F, Ye G, Abreo KD, Latif S, Zibari GB. Successful orthotopic liver transplantation after trimethoprim-sulfamethoxazole associated fulminant liver failure. Clin Transplant. 2003;17:461-4.

3. Thies PW, Dull WL. Trimethoprim-sulfamethoxazole-induced cholestatic hepatitis: inadvertent rechallenge. Arch Intern Med. 1984;144:1691-2.
4. Kouklakis G, Mpoumponaris A, Zezos P, Moschos J, Koulaouzidis A, Nakos A, et al. Cholestatic hepatitis with severe systemic reactions induced by trimethoprim-sulfamethoxazole. Ann Hepatol. 2007;6:635 .

5. Abi-Mansur P, Ardiaca MC, Allam C, Shamma'A M. Trimethoprimsulfamethoxazole-induced cholestasis. Am J Gastroenterol. 1981;76: 356-9.

6. Kowdley KV, Keeffe EB, Fawaz KA. Prolonged cholestasis due to trimethoprim sulfamethoxazole. Gastroenterology. 1992;102:214850 . 
Faria LC et al.

7. Muñoz SJ, Martinez-Hernandez A, Maddrey WC. Intrahepatic cholestasis and phospholipidosis associated with the use of trimethoprimsulfamethoxazole. Hepatology. 1990;12:342-7.

8. Ogilvie AL, Toghill PJ. Cholestatic jaundice due to co-trimoxazole. Postgrad Med J.1980; 56: 202-04.

9. Nair SS, Kaplan JM, Levine LH, Geraci K. Trimethoprimsulfamethoxazole-induced intrahepatic cholestasis. Ann Intern Med. 1980;92:511-2.

10. Steinbrecher UP, Mishkin S. Sulfamethoxazole-induced hepatic injury. Dig Dis Sci. 1981;26:756-9.

11. Coto H, Mcgowan WR, Pierce EH Jr, Thomas E. Intrahepatic cholestasis due to trimethoprim-sulfamethoxazole. South Med J. 1981;74:897-8.
12. Lee WM. Drug-induced hepatotoxicity. N Engl J Med. 2003;349:47485 .

13. Ruiz-Irastorza G, Montejo M, Ituarte J, Aguirre C. Colestasis prolongada tras dosis única de cotrimoxazol. Rev Clin Esp. 1996;196:87-8.

14. Altraif I, Lilly L, Wanless IR, Heathcote J. Cholestatic liver disease with ductopenia (vanishing bile duct syndrome) after administration of clindamycin and trimethoprim-sulfamethoxazole. Am J Gastroenterol. 1994;89:1230-4.

15. Yao F, Behling CA, Saab S, Li S, Hart M, Lyche KD. Trimethoprimsulfamethoxazole-induced vanishing bile duct syndrome. Am J Gastroenterol. 1997;92:67-9. 